\title{
Model Building Of College English Teaching Ability Training Under Education Reform Environment
}

\author{
Ting $\mathrm{Han}^{1, \text { a }}$ \\ ${ }^{1}$ Hanjiang Normal University, Shiyan city, Hubei Province, China \\ a852551531@qq.com
}

Keywords: Reform of education, College English, English teaching, Training mode

\begin{abstract}
As the international talent competition intensified, the cultivation of college students thinking ability has become an important content of college English education, and cultivates the ability of college students in the institutions of higher learning education occupies an important position. But in colleges and universities are not optimistic about the present situation of college students' thought ability, all kinds of problems emerge in endlessly, hindered the advance of the college students' thinking ability training. In this article, the author will start from the connotation and function of thinking, through analyzing the current situation of college English teaching ability training, build a strong feasibility of college English ability training mode.
\end{abstract}

\section{Introduction}

With the acceleration of globalization, the international talent competition is increasingly fierce, the west to the cultivation of students ability, attaches great importance to in the United States, the thinking has been listed as one of the important goals of higher education, and permeate to the interdisciplinary teaching. But in our country, although have realized the important role of thinking in higher education, but the status of the college students' ability is not optimistic [1]. Especially in college English teaching, the exam-oriented education is given priority to with imparting knowledge, memory for a long time, ignoring the cultivation of thinking ability, with the reform of college English, more and more studies begin to explore college English culture in the new period, the Chinese ministry of education in the college English curriculum requirements and the training of college English students thinking as one of the aims of education. Tries to find the effective ways to improve the ability of college English class, the college English classroom maximum efficiency, thus to improve the situation of college English "sonic".

The influence of the traditional college English exam-oriented education, teachers only teach English knowledge, forcing students blindly memory, reciting words, sentence patterns and classic text, completely ignore the cultivation of students' English ability [1]. Along with the advancement of college English teaching reform, the focus gradually shifted to the college English teaching in the new period for the cultivation of students' ability, correctly grasp the concept of thinking and action is the precondition of efficient training students' ability.

\section{The concept of teaching ability}

"Thinking capacity" means thinking ability, judgment ability and the ability to solve the problem. Western scholars is multi-purpose "critical thinking" concept, in English as "critical thinking". Many scholars in China put it into "critical thinking". It is translated into "high-level thinking ability", after the foreign language educational world discussion, finally determined to "thinking", the reason is "thinking" translation more can reflect the training objectives of higher education in China, it covers the college students should have the ability of abstract thinking, logical thinking ability, reasoning and arguments evaluation ability effectively [1]. It not only covers the college students should have the abstract thinking ability and logical thinking ability, reasoning ability effectively, also contains the spirit of independent thinking, proofed, innovative spirit, etc. Thinking is a thinking skills, is also a kind of personality and temperament. Speculation is a way of thinking, is also a kind of thinking ability. 


\section{The importance of teaching ability}

American education, Dewey thought education main purpose is to learn to think. Abroad some university English department admits the importance of thinking in its training objectives. They think "in English learning should also focus on the students' ability of thinking, the analysis of complex information ability which faces line information theory to develop a persuasive argument the cultivation of the ability of these should always be in the center of the English learning". So the cultivation of thinking has become an integral part of the western education system. The end of last century English major domestic began to pay attention to the cultivation of thinking. In 1988, Y.Sh. Huang "speculative absence" speaks foreign languages department students in thinking ability weak problem into the English teaching reform in the field [2]. However, many studies have shown that Chinese college students generally lack of ability. Many scholars and foreign language education experts have realized the importance of cultivating college students' ability. China's ministry of education in "college English curriculum requirements" puts forward the training of college English students thinking as one of the aims of education and the training of college English students thinking of specific requirements. In the extremely competitive world background, China needs a large number of analysis, reasoning, evaluation and so on speculative ability of talents, to enhance its international status. So cultivate and improve college students' ability to every aspect of national development has very important significance.

The content depends on the mode of comprehensive skills training, listening, speaking, reading and writing the four language skills training in knowledge acquisition process is helpful to improve the efficiency of the students' interest in learning and language acquisition [2]. Build content depends on the type of teaching refers to the language teaching in the teaching of a subject or a subject content, combine language learning and knowledge learning, to raise the students discipline knowledge and cognitive ability, promote the improvement of their language content depends on the type of teaching to unify the language form and meaning of learning, to eliminate the language learning in most of the education environment and subject knowledge to study the status of human segmentation, is helpful to inspire students through purpose language thinking \& learning new knowledge, help students read listen to write four language skills naturally together.

\section{The present status of speculative ability training in college English teaching}

Some researchers will thinking called "thinking", or "Critical thinking", etc., it is the crystallization of scholars sweat and wisdom. Opinions vary about the concept of thinking, but in its basic meaning, the author thinks that thinking should include two aspects: one is the theoretical skills and ways, namely, cognitive ability [3]. These two aspects is a closely linked, integral whole. The author thinks that, thought as a kind of significance and high value for thinking individual reflective thinking ability, judge is its core content. In short, is to use a series of skills and knowledge as the standard of evaluation and thinking ability, based on the thinking includes two aspects of content, cultivate students way of thinking should be focusing on speculative skills and attitude and quality.

In college English teaching plays an important role to cultivate the students' ability. First of all, cultivating college students' English ability is to cater to the university reform, realize the talents training goal of English teaching important way [3]. At the start of the $1980 \mathrm{~s}$, speculative ability training has been listed as the education training goal in many countries, with the development of the society, college English teaching in China naturally arises at the historic moment with the teaching objectives, and it is also to cultivate innovative talents, the important measures to promote social development and progress. Second, the cultivation of the ability to induce students' positive thinking, active students thinking, is to cultivate students' innovative spirit and practice ability. Finally, ability cultivation is to cultivate the students' problem consciousness, promote students to think deeply about all kinds of problems, cultivate their question, explore, clear up a doubtful point, disambiguation, and ability of answering questions, to understand the essence laws, so as to improve the students' integrated English skills. 
Focusing on the mechanical memory, neglecting the students logic thinking. Affected by traditional examination-oriented English education thought, some English teachers feel more repetition of students, mechanical memory and recite, is the student adept, freedom, dealing with all kinds of English, the most important way to improve students' comprehensive English literacy, and do not pay much attention to the cultivation of students ability [1]. Then, in the daily English teaching, the teacher only know that let students blindly dictation, reading, and to solve the problem that students once encountered theme analysis, explore the problems such as process and reasons, thinking in a state of stagnation or short circuit immediately, students often fuzzy, mark, even in the teachers' questions link student collective "aphasia", normal teaching atmosphere has been broken and deadlock. Students are with dialectical thinking consciousness, but long-term thinking straight in their English study seriously hampered the student's thought, killed the question and creative spirit of students, and cannot cultivate students' critical thinking.

Do not do the coordinated development between perceptual knowledge and rational cognition. Due to improper teaching teachers or students they easy to rational knowledge, leading to the understanding of English events tend to stay at the perceptual level, cannot know from phenomenon to essence [4]. Some students tend to be good at and cling to the appearances of things which describe and presentation, show ego magnificently in the perceptual knowledge, once encountered, analyze the essence through the phenomena, especially in the face of some extremely complicated problem, students lose their exploring consciousness and to explore the direction and the students' thinking logic chaos, reasons things out the obvious, cannot grasp the main contradiction of things, realize the leap from perceptual to rational, completely solve all kinds of problems in English classroom learning. Investigate its objective cause, this is the teacher never attaches great importance to the students' perceptual knowledge and rational knowledge to the coordinated development of the reality.

Focus on practical application as a teaching, neglecting the interest. One of the most important teaching aim of English teaching is to cultivate the students' English communicative ability, causes the student to understand the cultural background of English-speaking countries thoroughly, broaden horizons, enrich their knowledge, active thinking, enhance the cultural identity under the premise of improving the students' integrated English literacy. Based on this goal, many English teachers of English should be practical as the core content of classroom teaching, and ignore the cultivation of student's interest and ability [4]. For most students, teach college English is for one's deceased father grind and employment and studying abroad service in the future, and based on true very little interest in English study, don't even exist. Teachers tend to instill in students' English learning in English teaching important ideas, innovative teaching modes, but ignored the students' interest, the poor students learning motivation, think passion is weak, cannot induce students in all aspects, multi-angle thinking, killing the student's curiosity and desire for knowledge, the students' lack of lasting inner driving force of learning foreign language.

\section{Ability training mode building of College English teaching}

Continuously encourage teachers and students to enhance the consciousness of speculative ability training. To the discretion of the college students' English ability training quality is directly related with English or not, to achieve the goal of cultivating innovative talents is the key of the college English teaching. College English teaching is not just a simple teaching and learning, teaching model of pure theoretical knowledge infusion to be being washed out gradually, imparting knowledge and cultivating ability should be both. Analogy, the cultivation of students' ability of individual educators should not only stay in theory level, but should be to carry out to every teachers and students. To achieve these goals, constantly encourage teachers and students to enhance the consciousness of thinking training. On the one hand, the university itself should give enough emphasis on college students' English thinking ability training [5]. Organize regular English educators through skills training, knowledge view, and the way such as academic study systematically theoretical teaching content, continuously enhance their own teaching consciousness, gradually will make English teachers consciously the actors and the knowledge system of cultivating 
the ability of speculative builders. Colleges and universities should, on the other hand, using a variety of ways to speculative consciousness of cultivating the ability of students and ideas into the depths of the soul, its importance to the students, teach students system, scientific thinking ability training method, and guide students to improve English comprehensive quality based on speculative ability training.

Rich teaching methods and teaching mode to cultivate ability. In order to cater to the trend of education reform and development in the new period, university English teachers must be based on students' thinking ability, in the English teaching practice actively explore diversified teaching methods and teaching mode, in order to cultivate students' ability. The author thinks that the cultivation of the ability depends on two kinds of teaching means: one is the Socratic Method [4]. It can inspire students' wisdom, induce students' positive thinking, is very important to improve students' logical ability. Set the question and answer and discuss how the link, so that the students in the context of teachers build the deep exploration of the speculative, complete answers to challenging problem, improve the students' ability of logical reasoning. Secondly, the content depends on the teaching methods. It is based on the academic content rather than a way of teaching grammar rules, is designed to target language as classroom teaching, to achieve the goal of enhancing students' cognitive ability and language skills development. It is based on the subjective status of students, make students knowledge discovery and experience, in order to stimulate students' potential speculative thinking, make students actively in English classroom teaching.

The innovation evaluation system, pay attention to ability examination. The cultivation of student's ability should not only reflect in college English classroom teaching, the innovation evaluation system, it is imperative to increase the content of the examination for students thinking ability [5]. The current college English curriculum evaluation system, involves the students thinking ability training the content of the feeble little, in order to enhance the teachers and students to the attention of the speculative ability training, should perfect the evaluation system, increasing ability in college English formative assessment examination content, enrich the examination and evaluation forms. Such as personal display or team preparation, brainstorming, both sides debate, write about it, write editorial and self-assessment should become an important approach to examining the speculative ability.

To create a classroom environment, encourage students to question and to ask questions. To cultivate students' positive emotion quality, stimulate their thinking, teachers must first change the ideas; change their podium "authority" role, groveling, and interaction with the exchange of students actively in class activities. Equality, relaxed classroom atmosphere are more beneficial to students' imagination, analytical judgment, to study effectively [5]. Therefore, the classroom should be according to actual teaching needs flexible layout, best equipped with easy to move the desks and chairs, convenient students in classroom activities, so that the students and between students, between students and teachers to achieve full words, information and communication.

To strengthen the autonomous learning, encourage personalized learning. Thinking level theory, points out that cognitive skills are the major form of thinking, include analysis, inference and evaluation skills. Learners adjust or management of cognitive processes through the way such as planning, monitoring and evaluation, planning ahead, selective attention, self-management, self-monitoring and self-evaluation and other strategies [4]. Learner training and master the cognitive skills is one of the effective methods of autonomous learning, and autonomous learning helps to cultivate their positive emotional traits.

The reform of evaluation way, give play to the role of formative assessment. Curriculum evaluation is an indispensable important component of the course teaching is important means to examine the effects of teachers and students and teaching [2]. Traditional way of evaluation mainly examines students vocabulary, grammar, listening and reading comprehension skills to grasp the situation, students just passively accept review, did not give full play to the initiative of participate in the test, motility and self reflection ability. In recent years, from the school examination to the university English four, six levels of tests of routines increasingly showing a modular and stereotyped tendency, draw the result teaching takes an exam the phenomenon is relatively serious, the students to 
take exams tactics, or cramming, expect assault coach book learning examination smoothly. So, even if passed the exam, students also are not equal to their language skills have been achieved, not to mention have good thinking [3]. Therefore, in order to develop students' thinking, in the reform of college English teaching objectives, curriculum setting and teaching methods at the same time, also need to improve the curriculum evaluation ways and means, specific can take the following measures.

\section{Summary}

Above all, to cultivate the students' ability in college English is to achieve the goal of cultivating the innovative talents feasibility measures, based on the thinking of the importance of students' learning and development, teachers should constantly play to their own subjective initiative, and using a variety of teaching methods, stimulate students' thought to stimulate the formation of students' critical thinking. But to cultivate the students' thinking ability is a long-term and arduous task, is not achieved overnight, need English teacher tireless, effort and practice step by step.

\section{References}

[1] H.Y. Ping, Foreign language teaching research based on the content of college, Foreign language teaching and research, 2008, vol.1, pp. 59-64.

[2] X.M. Liu, The theory of college English teaching ability training mode construction, Foreign language world, 2013, vol.5, pp.59-66.

[3] Y.Q. Qin, College English teaching to improve students' ability of effective methods of empirical research, Ocean university of China, 2014, vol.7, pp.25-29.

[4] M.L. Yu, A training mode building of thinking in English teaching, Campus English, 2014, vol.11, pp.28-32.

[5] Y.P. Liu, English speech teaching and the cultivation of ability, Foreign language art education research, 2009, vol.3, pp.49-52. 